\title{
Estudo comparativo de índices morfométricos das sub-bacias hidrográficas dos rios Fumaça e Glória a partir de técnicas de Geoprocessamento
}

\author{
Luciano Melo Coutinho ${ }^{1}$ \\ Roberto Avelino Cecílioº \\ ${ }^{1}$ Universidade Federal do Espírito Santo / Centro de Ciências Agrárias \\ Estudante de Mestrado em Ciências Florestais \\ Fernando de Abreu, 14 - 29.308-050 - Cachoeiro de Itapemirim - ES, Brasil \\ lcncoutinho@hotmail.com \\ ${ }^{2}$ Universidade Federal do Espírito Santo / Centro de Ciências Agrárias \\ Professor Adjunto / Bolsista de Produtividade em Pesquisa do CNPq \\ Av. Gov. Lindemberg, 316 (NEDTEC) - 29550-000 - Jerônimo Monteiro - ES, Brasil \\ racecilio@yahoo.com.br
}

\begin{abstract}
Considering the importance of the river basin as a system and environmental management unit, the present work follows the methodology proposed by Morphometric Characterization Christofolleti (1980), which is guided in classical authors, especially Horton (1945) and Sthraler (1952). The morphometric characterization of watersheds is intended to characterize the dynamic water from the main action, followed by the correlation between them from specific criteria. The river basins of Fumaça and Glória had its body measures developed from Geoprocessing techniques software SPRING 5.1.2 and ArcGIS 9.2 ®. It was found that the area of both basins has values and linear morphometric parameters close, but the River Glória is less prone to flooding, which is due to the smaller circular trends of the basin. The use of GIS proves to be a practical and reliable for environmental studies.
\end{abstract}

Palavras-chave: form factor, roundness, main channel, relief, base map, fator de forma, circularidade, canal principal, relevo, base cartográfica.

\section{Introdução}

Devido ao marcante histórico de uso inadequado dos recursos naturais pelo homem, é crescente, na atualidade, a preocupação com as questões ambientais, principalmente no que se refere à recuperação e conservação de recursos hídricos. Diversos ramos do conhecimento científico, como as Geociências, Engenharias, Ciências do Ambiente e as Ciências Biológicas, reconhecem a necessidade de repensar e contribuir com propostas conscientes destinadas a sanar as atuais questões relativas ao uso e conservação da água.

Bacia hidrográfica ou bacia de drenagem são terminologias utilizadas para caracterizar áreas superficiais cujas feições do terreno determinem processos específicos, entre eles a drenagem superficial de água de chuva e sedimentos carreados, originados de pontos distintos à montante e com destino comum à jusante. Estes materiais podem se depositar pelo trajeto ou se agregarem aos cursos de ordem superior ou ao oceano (Silva et al. 2005).

A água constituinte do deflúvio superficial de uma bacia hidrográfica é originada de diversas fontes, principalmente da precipitação, do lençol freático, e do escoamento superficial, ou ainda de outras bacias por meio do aporte subterrâneo. Os sedimentos podem incluir todo material particulado arrastado, o que se aplica a solos, sedimentos de diferentes granulometrias e matéria orgânica, sendo este um dos processos morfogenéticos mais dinâmicos de modelagem da paisagem terrestre (Christofolleti, 1980).

A opção pelo uso de bacia hidrográfica como unidade básica de gestão de recursos hídricos oferece a vantagem de uma delimitação precisa de áreas de estudo e por constituir 
um sistema ambiental com componentes e fatores dinâmicos próprios. Rodrigues e Adami (2005) reforçam a importância de se considerar os aspectos geomorfológicos e hidrológicos em estudos de bacias, além de se atentar para o uso de métodos adequados na delimitação.

O presente trabalho aborda as etapas da Caracterização Morfométrica das bacias dos rios Fumaça e Glória, por meio de Hierarquia Fluvial, Análise Linear, Análise Areal, Análise Hipsométrica e Perfil Longitudinal, tendo o suporte de técnicas de Geoprocessamento trabalhadas em Sistemas de Informação Geográfica (SIG).

\section{Material e Métodos}

\subsection{Caracterização da Área}

As sub-bacias dos rios Fumaça e Glória estão localizados ao sudeste do Estado de Minas Gerais entre as latitudes S $20^{\circ} 30^{\prime}$ e $21^{\circ} 20^{\prime}$ e as longitudes W $41^{\circ} 40^{\prime}$ e $42^{\circ} 45^{\prime}$, fazendo fronteira com o sul do Estado do Espírito Santo e norte do Estado do Rio de Janeiro. Estes rios se encontram na Bacia Hidrográfica do Rio Paraíba do Sul, a qual abrange, além do dois Estados citados, parte do leste do Estado de São Paulo.

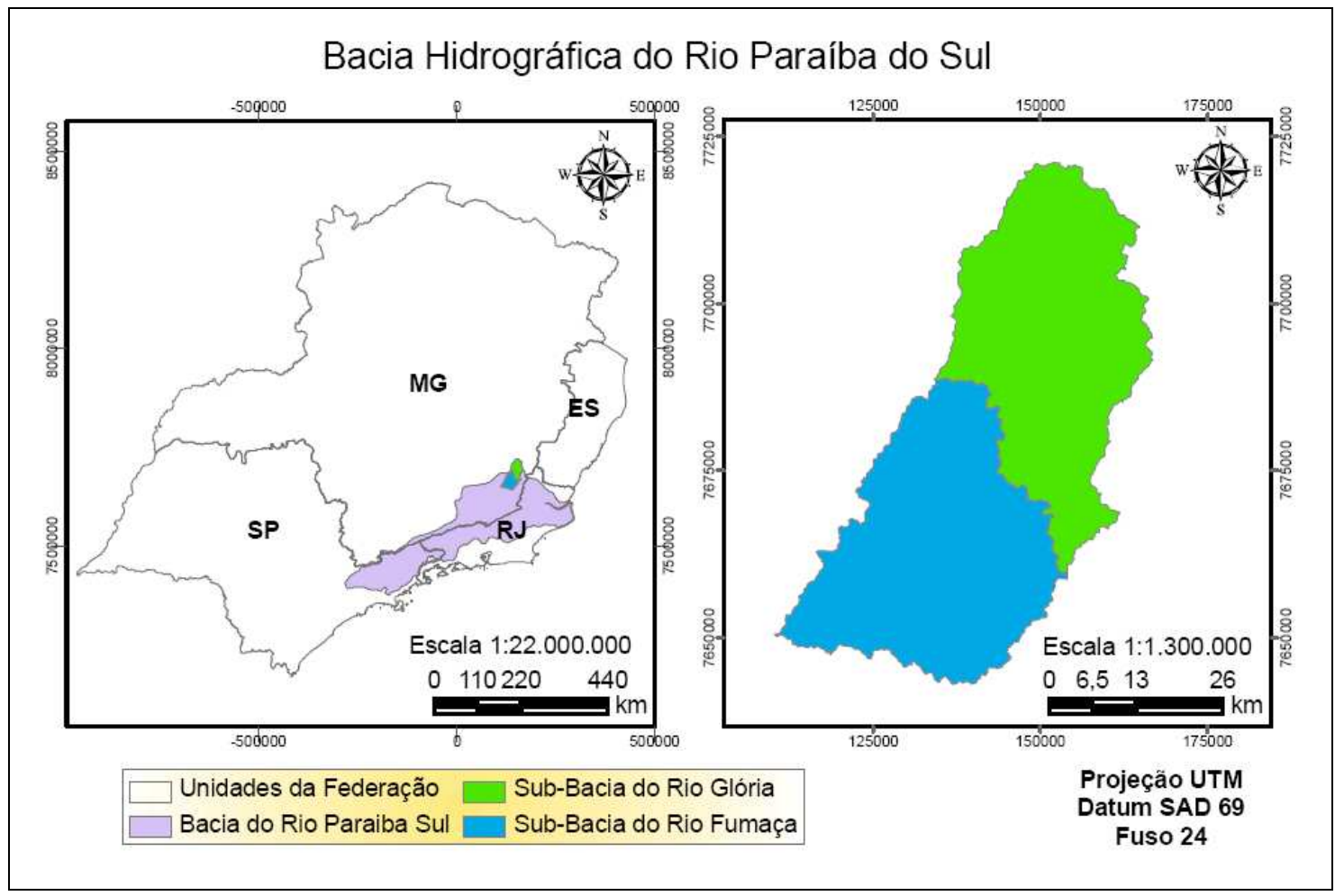

Figura 1: Localização das sub-bacias analisadas.

\subsection{Origem dos dados}

Como dados de altimetria foram utilizadas imagens Shuttle Radar Topography Mission (SRTM), geradas por dados de radar originais de sensores a bordo do ônibus espacial Endeavour, disponibilizados pela Empresa Brasileira de Pesquisa Agropecuária (EMBRAPA Monitoramento por Satélite). Estas imagens constituíram a base cartográfica do trabalho após tratamento e conversões. Os modelos numéricos de elevação são originais das cenas SF-23X-B e SF-23-X-D. Dentre suas informações técnicas constam formato GEOTIFF (16 bits), 
pixel com resolução espacial de 90mx90m, Sistema de Coordenadas Geográficas e Datum WGS-84 (Miranda, 2005).

Os SIG's utilizados foram o Sistema de Processamento de Informações Georeferenciadas (SPRING) na versão 5.1.2, disponível no site do Instituto Nacional de Pesquisas Espaciais (INPE), e o ArcGIS 9.2® disponibilizado pela empresa ESRI (Santos, 2007).

Entende-se que o uso de cartografia e SIG compõem um importante acessório para o estudo de bacias, pois permitem a elaboração de temas específicos e constituem um elemento de orientação do planejamento de uso e ocupação do terreno (Silva et al. 2003).

\subsection{Metodologia}

Os Modelos de Dados trabalhados no ambiente SIG foram do tipo Temático para hidrografia e Modelagem Numérica do Terreno (MNT) para altimetria, datum UTM SAD 69. Os pixels eram de dimensões de $10 \mathrm{mx} 10 \mathrm{~m}$, considerando o erro médio quadrático referente à escala 1:50000.

As imagens SRTM foram importadas para o SPRING no formato de grade e transformadas para isolinhas de formato Shapefile, com eqüidistância de 20 metros.

No aplicativo ArcMap foram realizadas as etapas de interpolação e geração da grade triangular (TIN), a qual foi convertida para o formato Raster. A partir do ArcToolbox foram identificados os canais fluviais, seguido da hierarquização de Sthraler (1952 apud Christofolleti, 1980) e delimitadas as bacias pelo divisor de águas. Estes processos foram realizados automaticamente no SIG a partir da Modelagem Numérica do Terreno, a qual pode indicar a direção do fluxo, de acordo com a metodologia apresentada por Santos (2007). O fluxograma das etapas realizadas em ambiente SIG estão apresentados na figura 2.

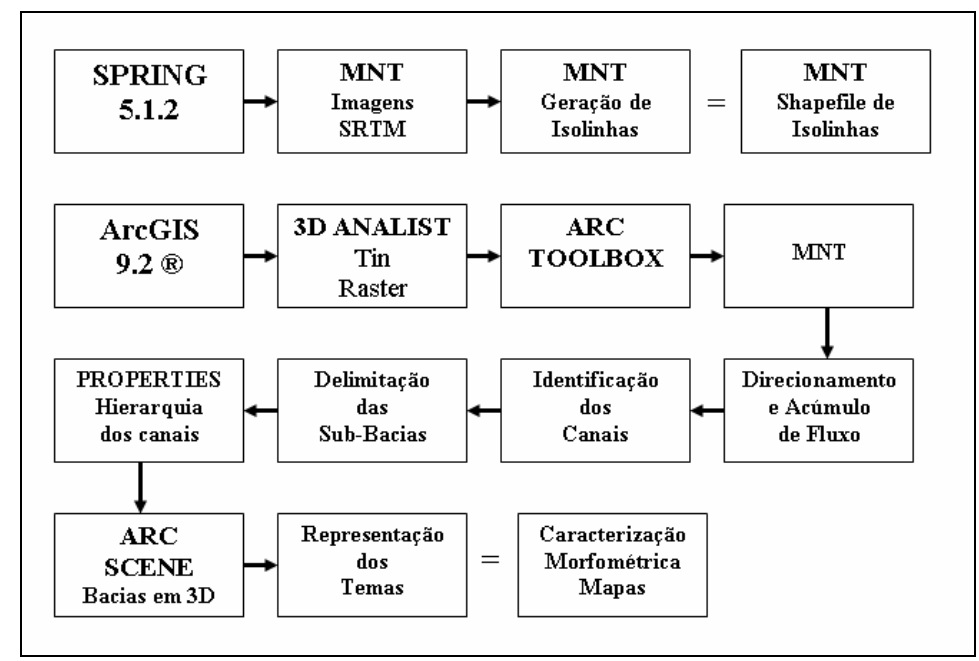

Figura 2: Fluxograma de preparo de material e de métodos

A caracterização morfométrica realizada abrangiu as etapas de Hierarquia Fluvial, Análise Linear, Análise Areal e Perfil Longitudinal, de acordo com Christofolleti (1980). Foram considerados parâmetros e representações específicas das sub-bacias, como área, perímetro, largura, comprimento do canal principal, comprimento axial e outros.

- Hierarquia Fluvial: foi feita a organização dos canais a partir da junção dos mesmos, sendo estes de $1^{\mathrm{a}}$ ordem os menores e isolados, de $2^{\mathrm{a}}$ ordem o encontro de dois canais de primeira 
ordem, de $3^{\mathrm{a}}$ ordem os que se formam por dois de segunda, e de $4^{\mathrm{a}}$ ordem a junção de dois de terceira, e assim sucessivamente, conforme a quantidade de bifurcações.

- Análise Linear: todos os canais de uma mesma ordem foram organizados, sendo somados seus comprimentos e a quantidade de canais de cada ordem, a partir da equação a seguir.

$\mathrm{L}_{\mathrm{m}}=\mathrm{L}_{\mathrm{N}} \mathrm{u}$. (soma dos comprimentos dos canais de cada ordem).

- Análise Areal: foram feitas as relações entre medidas de cada sub-bacia apresentadas na Tabela 1.

Tabela 1: Componentes e resultados prévios da Análise Areal.

\begin{tabular}{|c|c|c|c|}
\hline Processo & Objetivo & Ideal & Fórmula \\
\hline $\begin{array}{l}\text { - Coeficiente de } \\
\text { compacidade: }\end{array}$ & $\begin{array}{l}\text { Relaciona a bacia a um circulo, e quanto } \\
\text { mais próximo a } 1 \text {, mais sujeitas a inundação. }\end{array}$ & $\mathrm{Kc}<1,50$ & $\mathrm{Kc}=0,28 \sqrt{\sqrt{\mathrm{A}}}$ \\
\hline - Fator de forma: & $\begin{array}{l}\text { Relação entre largura e comprimento, para } \\
\text { comparação de bacias. }\end{array}$ & $\mathrm{F}<0,50$ & $\mathrm{~F}=\frac{\mathrm{A}}{\mathrm{L}^{2}}$ \\
\hline $\begin{array}{l}\text { - Índice de } \\
\text { circularidade: }\end{array}$ & $\begin{array}{l}\text { Quanto mais próximo de } 1 \text {, maior a } \\
\text { circularidade e sujeita a inundações. }\end{array}$ & Ic $<0,51$ & $\mathrm{IC}=\frac{12,57^{*} \mathrm{~A}}{\mathrm{P}^{2}}$ \\
\hline $\begin{array}{l}\text { - Densidade de } \\
\text { drenagem: }\end{array}$ & $\begin{array}{l}\text { Soma de comprimento dos canais, verifica a } \\
\text { velocidade da drenagem. }\end{array}$ & - & $\mathrm{Dd}=\frac{\mathrm{Lt}}{\mathrm{A}}$ \\
\hline
\end{tabular}

- Análise Hipsométrica: a curva hipsométrica é utilizada para uma representação das áreas que cada classe de altitude representa na bacia.

- Perfil Longitudinal: relacionaram-se o comprimento dos canais principais das sub-bacias e suas altitudes, representados graficamente pela relação entre hidrografia (eixo X) e altimetria (eixo Y).

Os resultados e produtos gerados em SIG foram organizados e representados tematicamente pelo aplicativo ArcMap, sendo transformados em mapas (layouts) de altimetria, declividade, orientação do terreno e hierarquia fluvial. As imagens em 3D foram geradas pelo aplicativo ArcScene para uma comparação em perspectiva das bacias.

\section{Resultados e Discussão}

Os valores obtidos a partir das equações de parâmetros morfométricos, apresentados na Tabela 2, indicam que as duas bacias apresentam poucas tendências a inundações, pois os coeficientes de compacidade se encontram afastados da unidade.

As medidas do comprimento do canal principal $(53,53 \mathrm{~km})$ e da largura média $(47,41 \mathrm{~km})$ da sub-bacia do Rio Glória lhe conferem um menor fator de forma $(0,28)$, enquanto este parâmetro se mostra elevado para a sub-bacia do rio Fumaça $(0,88)$, sendo do ideal que este coeficiente fosse inferior a 0,50 .

Considerando os valores dos índices de circularidade de ambas as sub-bacias, ambos se encontram afastados do valor ideal $(0,51)$. Este parâmetro deve ser analisado com atenção, pois chuvas intensas e simultâneas na extensão de uma bacia pode se concentrar rapidamente no canal principal.

A densidade de drenagem de ambas pode ser considerada fraca de acordo com a proposta de Villela e Mattos (1975), os quais consideram os índices de $0,5 \mathrm{~km} / \mathrm{km}^{2}$ pobres e acima de $3,5 \mathrm{~km} / \mathrm{km}^{2}$ com bem drenadas. O Rio Fumaça apresentou maior densidade de drenagem 
0,40 km/ $\mathrm{km}^{2}$, embora tenha menor área, apresenta maior quantidade de canais (113) e melhor posicionamento na hierarquização ( $5^{\mathrm{a}}$ ordem), cujas medidas se encontram na Tabela 3.

Tabela 2: Medidas lineares e parâmetros morfométricos.

\begin{tabular}{|c|c|c|}
\hline Item & Rio Fumaça & Rio Glória \\
\hline Área Total $\left(\mathrm{km}^{2}\right)$ & 1110,08 & 1095,49 \\
\hline Perímetro (km) & 183,76 & 200,21 \\
\hline Canal Principal Total (km) & 53,53 & 79,39 \\
\hline Comprimento Axial (km) & 35,32 & 62,24 \\
\hline Largura $(\mathrm{km})$ & 47,41 & 31,30 \\
\hline Coeficiente de compacidade & 1,54 & 1,69 \\
\hline Fator de forma & 0,88 & 0,28 \\
\hline Índice de circularidade & 0,41 & 0,34 \\
\hline Densidade de drenagem $\left(\mathbf{k m} / \mathbf{k m}^{2}\right)$ & 0,40 & 0,37 \\
\hline Altitude Máxima (m) & 1560 & 1940 \\
\hline Altitude Média (m) & 550 & 760 \\
\hline Altitude Mínima (m) & 180 & 180 \\
\hline Declividade Máxima (\%) & 366,21 & 527 \\
\hline Declividade Média (\%) & 24,25 & 24,72 \\
\hline Declividade Mínima (\%) & 0 & 0 \\
\hline Orientação do Relevo $\left(\mathrm{km}^{2}\right)$ & Sul $(154,51)-N(69,20)$ & Sul $(152,43)-N(66,36)$ \\
\hline
\end{tabular}

As curvas hipsométricas foram geradas a partir de analise Geoestatística do MNT. No Rio Fumaça predomina a classe entre $250-500 \mathrm{~m}$, próximas a média de $550 \mathrm{~m}$. Na bacia do Rio Gloria predomina a classe entre $750-1000 \mathrm{~m}$, a qual se distancia da média de $760 \mathrm{~m}$.

Tabela 3: Hierarquia e mensuração dos canais

\begin{tabular}{c|cccccc}
\hline Ordem de & \multicolumn{3}{|c}{ Rio Fumaça } & \multicolumn{3}{c}{ Rio Glória } \\
\cline { 2 - 7 } Straler & Quantidade & Medida (km) & Média (km) & Quantidade & Medida (km) & Média (km) \\
$\mathbf{1}^{\mathbf{a}}$ & 86 & $233,94 \mathrm{~km}$ & 2,72 & 77 & 203,45 & $-2,64$ \\
$\mathbf{2}^{\mathbf{a}}$ & 20 & 105,32 & 5,26 & 15 & 121,83 & 8,12 \\
$\mathbf{3}^{\mathbf{a}}$ & 4 & 88,33 & 22,08 & 3 & 33,96 & 11,32 \\
$\mathbf{4}^{\mathbf{a}}$ & 2 & 14,56 & 7,28 & 1 & 52,60 & - \\
$\mathbf{5}^{\mathbf{a}}$ & 1 & 6,59 & - & - & - & - \\
TOTAL & 113 & 448,74 & 3,30 & 96 & 411,84 & 4,29 \\
\hline
\end{tabular}

Com base nos perfis topográficos da Figura 3, verifica-se menor possibilidade de inundações na bacia do Rio Glória, principalmente quando associados aos valores de fator de forma, pois seu canal principal indica uma drenagem bem distribuída ao longo de maior extensão. O canal principal do Rio Fumaça apresenta grande extensão em uma menor área, o que se deve a sinuosidade deste canal, seguido de um rompimento brusco entre as altitudes de $600 \mathrm{~m}$ e $190 \mathrm{~m}$ em uma extensão inferior a $1500 \mathrm{~m}$, o que pode ser um fator agravante considerando-se litologia, infiltração, escoamento, velocidade do fluxo e erosividade.

Tabela 4: declividade do terreno segundo classes da EMBRAPA.

\begin{tabular}{c|ccc}
\hline Declividade & Categoria & Rio Fumaça & Rio Gloria \\
\hline $0-3 \%$ & Plano & $142,10 \mathrm{~km}^{2}-12,83 \%$ & $128,60 \mathrm{~km}^{2}-11,75 \%$ \\
$3-8 \%$ & Suave Ondulado & $88,18 \mathrm{~km}^{2}-7,96 \%$ & $92,69 \mathrm{~km}^{2}-8,47 \%$ \\
$8-20 \%$ & Ondulado & $285,69 \mathrm{~km}^{2}-25,79 \%$ & $292,77 \mathrm{~km}^{2}-26,75 \%$ \\
$20-45 \%$ & Forte Ondulado & $433,00 \mathrm{~km}^{2}-39,08 \%$ & $425,94 \mathrm{~km}^{2}-38,91 \%$ \\
$45-75 \%$ & Montanhoso & $150,89 \mathrm{~km}^{2}-13,62 \%$ & $141,03 \mathrm{~km}^{2}-12,88 \%$ \\
$>75 \%$ & Forte Montanhoso & $8,07 \mathrm{~km}^{2}-0,73 \%$ & $13,52 \mathrm{~km}^{2}-1,24 \%$ \\
\hline
\end{tabular}


Em uma análise da declividade das bacias, cujos resultados se encontram na tabela 4, as bacias apresentam predominância do relevo tipo forte ondulado (entre 45 e $75 \%$ de inclinação). Maiores declividades podem aumentar os índices de escoamento e diminuir a infiltração. Com base em uma comparação entre área e declividade verifica-se que o Rio Fumaça apresenta tendências de rápido escoamento e maior concentração, pois sua área de relevo plano $\left(142,10 \mathrm{~km}^{2}\right)$ é maior que a área plana do Rio Gloria $\left(128,60 \mathrm{~km}^{2}\right)$.

Representações em 3D são utilizadas para uma visualização geral de áreas, figura 5. A bacia do Rio Fumaça apresenta mudanças bruscas de altitudes devido a um relevo de patamares, o que pode indicar escoamento intensivo em áreas de transição de altitudes.

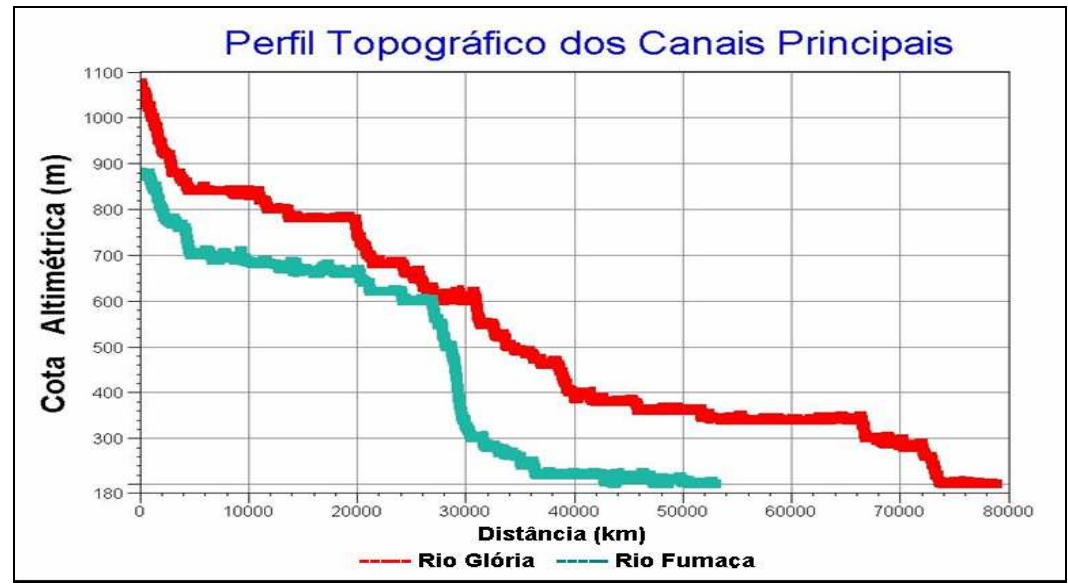

Figura 3: Perfis gerados a partir dos canais principais dos rios.
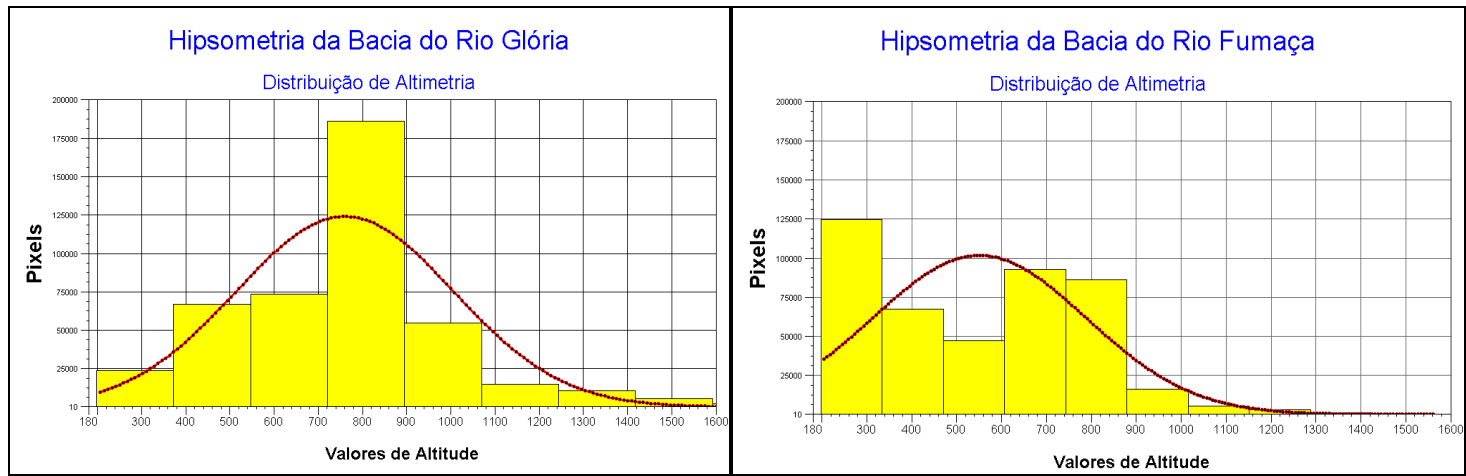

Figura 4: representações hipsométricas das bacias.

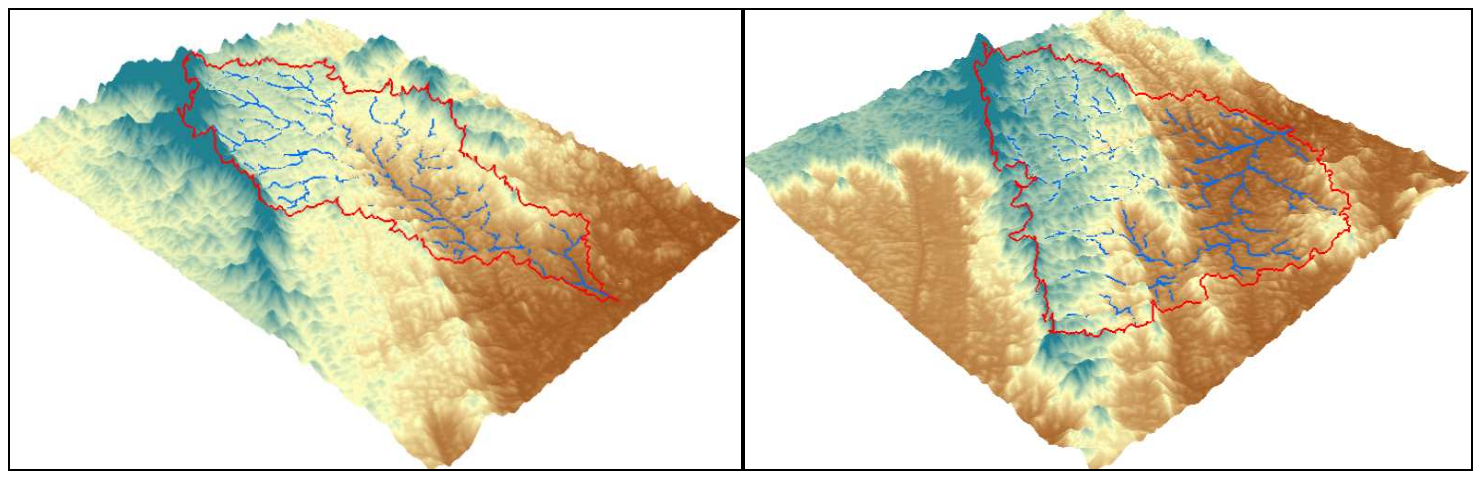

Figura 5: Visualização em 3D das sub-bacias dos rios Glória e Fumaça. 


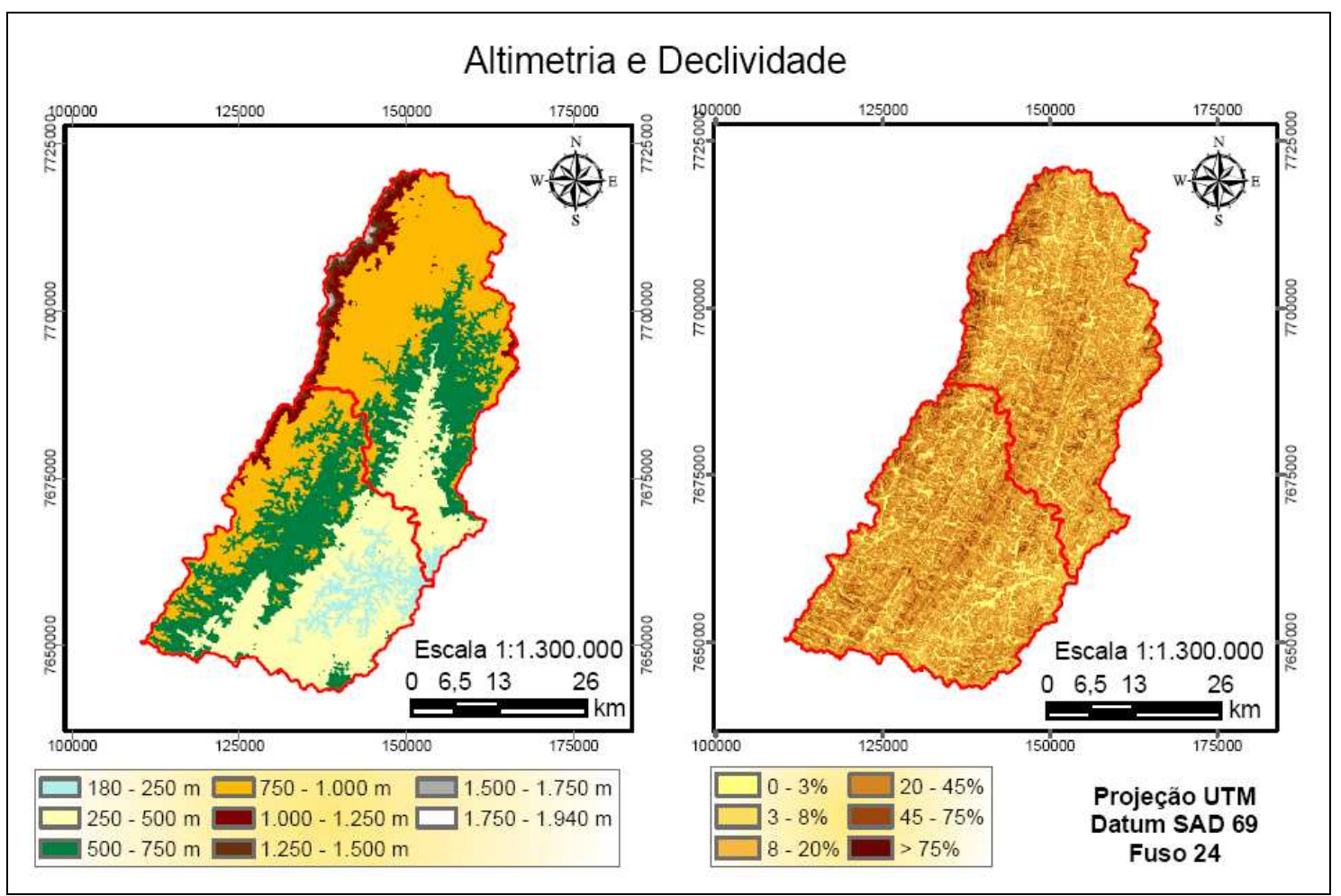

Figura 6: layout de altimetria e declividade do terreno.

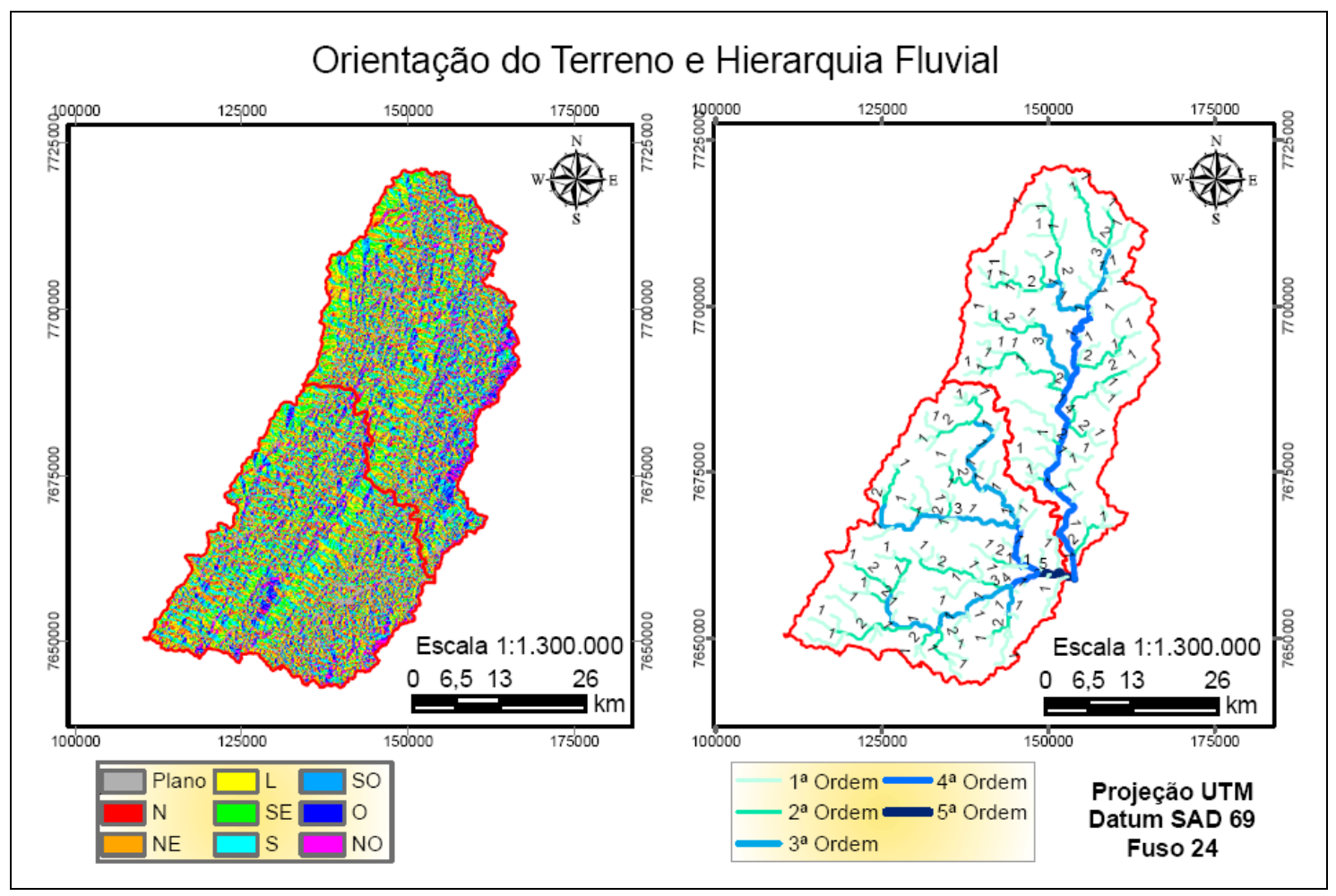

Figura 7: layout de orientação do terreno e hierarquia fluvial. 
Na figura 7 consta o mapa de orientação do terreno, utilizado para indicar o fator de incidência solar na bacia, o que pode afetar as relações de precipitação e deflúvio. Segundo Lima (2008), bacias com relevo norte apresentam maiores taxas de deflúvio quando comparadas as de relevo sul, sendo no caso das duas bacias o destaque para orientação sul.

\section{Conclusão}

Os valores da análise morfométrica das bacias do Rio Fumaça e do Rio Glória indicam poucas tendências a inundações quando comparadas com os índices aceitáveis propostos pela verificação dos parâmetros. Entretanto, quando comparadas entre si, a bacia do Rio Glória apresenta melhores resultados, principalmente ao se considerar a relação entre comprimento e largura, cujo resultado se verifica em um fator de forma de 0,28.

A utilização de SIG's é uma medida confiável para estudos ambientais, uma vez que o uso de dados georeferenciados garante precisão cartográfica e matemática, visualização de fatores, geração e correlação de temas e ganho de tempo.

Imagens SRTM permitem a confecção de base cartográfica confiável, não sendo sua pequena resolução espacial $(90 \mathrm{~m}$ x $90 \mathrm{~m})$ um fator limitante para tais trabalhos, pois estas podem ser refeitas pela geração de isolinhas com eqüidistância predeterminada e reclassificadas com novo valor de pixel de acordo com os objetivos da pesquisa.

\section{Referências}

Livro

CHRISTOFOLLETI, A. Geomorfologia. São Paulo, Edgard Blucher. 2a ed, 1980.

DRUCK, S. (et al). Análise Espacial de Dados Geográficos. Planaltina, DF: Embrapa Cerrados, 2004.

LIMA, W. de P. Hidrologia Florestal aplicada ao manejo de bacias hidrográficas. Piracicaba, SP: USPESALQ, $2^{\text {a }}$ edição, 2008.

RODRIGUES, C.; ADAMI, S. Técnicas fundamentais para o estudo de bacias hidrográficas, in: VENTURI, L.A.B. Praticando Geografia: técnicas de campo e laboratório em geografia e análise ambiental. São Paulo: Oficina de Textos, 2005.

SILVA, A. M. (et al). Erosão e Hidrossedimentologia em Bacias Hidrográficas. São Carlos: RiMa, 2003.

SANTOS, A. R. dos. ArcGIS 9.1 total: aplicações para dados espaciais. Vitória, ES: Fundagres, 2007.

VILLELA, S.M.; MATTOS, A. Hidrologia aplicada. São Paulo: McGraw-Hill do Brasil, 1975.

\section{Referências de Internet:}

MIRANDA, E. E. de (Coord.). Brasil em Relevo. Campinas: Embrapa Monitoramento por Satélite, 2005. Disponível em: <http://www.relevobr.cnpm.embrapa.br>. Acesso em: 26 set. 2009.

"SPRING: Integrating remote sensingand GIS by object-oriented data modelling" Camara G, Souza RCM, FreitasUM, Garrido J Computers \& Graphics, 20: (3) 395-403, May-Jun 1996. 